Nunt. Antiquus, Belo Horizonte, v. 14, n. 2, p. 181-191, 2018

\title{
O canto de Orfeu em dísticos elegíacos: lamento e exaltação no prefácio II de $O$ rapto de Prosérpina
}

\section{Orfeu's Song in Elegiac Couplets: Lament and Exaltation in the Preface II of The Abduction of Proserpine}

\author{
Heloísa Maria Moraes Moreira Penna \\ Universidade Federal de Minas Gerais (UFMG), Belo Horizonte, Minas Gerais / Brasil \\ heloisampenna@hotmail.com
}

Resumo: O presente trabalho contém breve estudo sobre o prefácio do livro II de $O$ rapto de Prosérpina, do poeta alexandrino Claúdio Claudiano. Busca analisar a presença de Orfeu e seu hino a Hércules, numa narrativa de épica mitológica, cujo tema é o rapto da filha de Ceres por Plutão. A forma do prefácio, em dísticos elegíacos, também é focalizada e se justifica pelo conteúdo desse poema-prelúdio, um verdadeiro hino de triunfo à chegada de Hércules a Trácia e à harmonização da natureza, pelo canto de Orfeu. As potencialidades do metro, em que o solene hexâmetro é seguido pelo enfático pentâmetro, nas penas de um habilidoso escritor, é o que garante o tom de lamento e exaltação que antecipa o sofrimento da raptada e a alegria do raptor.

Palavras-Chave: $O$ rapto de Prosérpina; Cláudio Claudiano; prefácio do livro II; Orfeu; Hércules; dístico elegíaco.

Abstract: The present work contains a brief study of the preface to Book II of The Abduction of Proserpine, by the Alexandrian poet Claudius Claudianus. It seeks to analyze the presence of Orpheus and his hymn to Hercules through the narrative of a mythological story, whose theme is the abduction of the daughter of Ceres by Pluto. The form of the preface, in elegiac couplets, is focused on and justified by a poem-prelude, a triumphal hymn to the arrival of Hercules to Thrace, and to the harmonization of Nature by the song of Orpheus. In the writing feathers of a skilled writer, it is the potentialities of the rhythm, in which the solemn hexameter is followed by the emphatic pentameter, that guarantees the tone of lament and exaltation that anticipates the suffering of the abducted and the joy of the abductor.

Keywords: The Abduction of Proserpine; Claudius Claudianus; Preface of the Book II; Orpheus; Hercules; elegiac couple. 


\section{Sobre o poeta e sua obra}

Como acontece com muitos escritores da Antiguidade, pouco se sabe da biografia de Claudiano, o que leva os estudiosos a extrair informações da obra do próprio autor. Segundo Cameron (1970, p. 189), Cláudio Claudiano, um intelectual alexandrino, partira do Egito, provavelmente, em 391 d.C., e se instalara na corte de Milão, como protegido do general Estilicão. Pelo nível de seus escritos, ele deve ter tido uma boa formação retórica, assegurada provavelmente pelas boas condições financeiras de sua família. ${ }^{1}$ Além disso, escreveu em grego, sua língua materna, e em Latim. Na Itália, dedicou-se a escrever panegíricos, poemas políticos e obras de cunho mitológico. Entre elas, a épica em miniatura, De Raptu Proserpinae, como a classifica Toohey, (1992, p. 211). O sucesso de suas obras foi tal que uma estátua de bronze, em sua homenagem, foi erigida no Fórum de Trajano, pelo senado romano, cuja inscrição conservada faz-lhe um elogio cheio de superlativos como, uir clarissimus ("homem famosíssimo"), praecloriosissimus poetarum ("o mais célebre dos poetas"). ${ }^{2}$

O mito escolhido para a escritura de sua épica mitológica, a história de Ceres e Prosérpina, está longe do ineditismo. Aparece desde cedo na literatura grega (Hino a Deméter, de Homero) e segue referenciada nos líricos e tragediógrafos, tendo em Roma presença nos compiladores de manuais mitológicos (HIGINO, CXVI.Proserpina; CXVII.Triptolemus), nos Fasti (IV) e Metamorfoses (V) de Ovídio. O rapto de Prosérpina/Perséfone, filha de Ceres/Deméter, por Plutão/ Hades, mereceu de Claudiano uma extensão considerável (1.108 versos), assim distribuídos: livro I: A ira de Plutão, com 288 versos; o livro II: O rapto de Prosérpina, com 372 versos; e o livro III: A busca de Ceres, com 448 versos.

Os livros I e II vêm introduzidos por prefácios em dístico elegíaco e de natureza metapoética. $\mathrm{O}$ do livro I (12 versos) evoca a coragem e a audácia do primeiro navegador (referência a Jasão) que com um navio

${ }^{1}$ Charlet (1991, p. IX).

${ }^{2}$ Cf. Charlet (1991, p. XIV, nota de rodapé 25). 
de sua invenção (inuenta naue, v. 1), ainda rude (rudibus remis, v. 2), progressivamente se arriscou da navegação de cabotagem até o alto mar, enfrentou as tempestades do Egeu e do mar Jônio (Aegeas hiemes, Ioniumque). A leitura em chave alegórica nos leva a relacionar o navio com a obra poética; a navegação com o gênero poético; o piloto com o poeta; a tempestade e a bonança com as variações típicas do discurso épico.

No prefácio do livro II, o poeta apresenta-nos a figura do cantor Orfeu. Num primeiro momento, sua lira está muda e, na ausência de seus acordes, a natureza e as ninfas se ressentem. Após a chegada de Hércules a Trácia, no entanto, Orfeu se anima e canta os trabalhos do herói tiríntio. A natureza se põe em festa. Claudiano se compara a Orfeu e canta um outro Hércules, Florentino (prefeito de Roma em 396 d.C. ou um filósofo?), que o inspira.

\section{O prefácio do Livro II}

O prefácio do livro II contém 52 versos divididos em 26 dísticos elegíacos. Pela identidade sintática, semântica e estilística eles podem ser agrupados em estrofes de quatro versos: 1-8, silêncio de Orfeu e desespero da natureza; 9-16, chegada de Hércules e retomada da lira; 1728, efeito do canto de Orfeu no reino vegetal e animal; 29-48, celebração dos trabalhos de Hércules; 49-52, dedicatória a Florentino: identificação do amigo com Hércules e do poeta com Orfeu.

\subsection{A figura de Orfeu}

O poema que introduz o livro II é em dísticos elegíacos, e seu conteúdo, um tanto "deslocado da temática épica", segundo Hall (1969, p. 94), faz, a meu ver, perfeita conexão com a narrativa que o segue: a consumação do rapto de Prosérpina por Plutão. Orfeu, graças aos acordes mágicos da lira, atravessou os portões de Dite e teve acesso às regiões infernais em busca de Eurídice. Essa experiência lhe credencia, portanto, a ser o inspirador do poeta que ousa, num detalhado relato, descrever o submundo com incomum conhecimento. Além disso, podemos traçar 
um paralelo entre a figura do Orfeu, desolado pela falta de Eurídice, com a de Ceres entristecida com a perda de sua filha (fato narrado no livro III). As reações de ambos, do vate e da deusa, são equivalentes: não desistem de seu amor e vão às últimas consequências para recuperálo. Eurídice e Prosérpina são, com finalidades diferentes, raptadas por Plutão e, ambas, noivas, têm no casamento uma sentença de morte. E o paralelo entre Orfeu e Ceres, como mostra Claudiano, pode se estender à influência que ambos têm sobre a natureza: enquanto Orfeu estava indiferente, as ninfas choravam (lugebant Nymphae, II, 3); os rios se entristeciam (flumina maesta, II, 6); a natureza cruel das feras retornava (saeua feris natura redit, II, 6); enfim, os duros montes (duri montes) e a floresta seguidora da lira (silua Bistoniam secuta, II, 8) deploraram seu silêncio (illius fleuere silentia, II, 7). No entanto, com a chegada de Hércules a Trácia, Orfeu encontra uma razão para retomar seu ofício, e a natureza se beneficia dessa mudança. Ceres, por sua vez, ao ficar sem sua filha passa de mãe dos mortais (genetrix mortalibus, III, 39) a cruel madrasta (in dirae subito mores transisse nouercae, III, 40) ao castigar os campos (campos horrere, III, 37) e promover a escassez de frutos (nullis fructibus annum, III, 38). O retorno de sua felicidade ao saber de sua filha (natae laetata repertae, III, 51) trará, como recompensa, a distribuição de espigas, fruto até então desconhecido dos homens (ignotas populis aristas, III, 53).

Ambos, Ceres e Orfeu, são figuras ligadas à era de Saturno, à idade de ouro em que o mundo vivia magicamente a fartura espontânea dos campos e rios. A punição de ambos provoca, em última análise, a metamorfose programada do mundo.

\subsection{A presença de Hércules}

Hércules, personagem de muito prestígio entre os poetas, foi o único ser que reanimou Orfeu, entristecido com a perda de Eurídice. Esse poder do tiríntio advém de sua força moral - seus passos trazem a paz (paciferus pes, Prefácio do L. II, v. 10) - e física - pois a tudo submetia com sua mão forte (forti manu, Prefácio do L. II, v. 30): assim, completou os dozes trabalhos e livrou o mundo de seres monstruosos. Numa leitura 
alegórica dessa presença, a escolha teria sido feita em comparação com as viagens de Florentino pelo mundo romano. ${ }^{3}$ Marrón (2011, p. 56) analisou o prefácio do II livro e observou a ênfase dada ao episódio da transferência do peso do mundo dos ombros de Atlas para o de Hércules:

Dos dezesseis versos em discurso direto que o canto de Orfeu abarca, os doze primeiros apresentam sumariamente sete dos trabalhos de Hércules e os quatro restantes se expandem na descrição do estupor gerado pela substituição dos ombros de Atlas pelos do herói como novo sustentáculo do mundo.

A escolha de Hércules como o novo sustentáculo do mundo, segundo Marrón, tem a ver com "o destinatário do poema de Claudiano" que, ao ser nomeado "Tyrinthius alter, deveria ser "outro Hércules", ou seja "partícipe de um tipo heroico diferente, próximo ao encarnado por Epicuro no poema de Lucrécio e, portanto, mais estreitamente ligado à figura divinizada do filósofo que à figura do imperador (MARRÓN, 2011, p. 58).

A alusão aos trabalhos de Hércules aparece a partir do verso 33 do prefácio do livro II, em ordem arbitrária e com a ausência de um deles: falta a menção aos estábulos de Augias. De forma sumária, referidos ora em meio verso, ora em um ou dois, os trabalhos iniciam-se pelo touro que "estremece as cidades de Creta com seus mugidos" (... dictaeas quatiens mugitibus urbes/ taurus, vv. 33-4); seguem com a "ira do estígio cão que não aterrorizou [Hércules]" (... nec Stygii terruit ira canis, v. 34); o leão de Némea, "que retornará aos céus como constelação" (non leo sidereos caeli rediturus ad axes, v. 35); o javali, "glória do monte de Erimanto" (non Erymanthei gloria montis aper, v. 36); e a conquista do "cinturão amazônico" de Hipólita (soluis Amazonios cinctus..., v. 37); depois vêm as aves do lago Estinfalo atingidas "com o arco" (... Stymphalidas arcu/ appetis, vv. 37-8); a morte do gigante Gérion e a condução "dos rebanhos do ocidente" (... occiduo ducis ab orbe greges, v. 38); seguem ainda com a morte do gigante Anteu e a destruição da hidra de Lerna (... cadere

${ }^{3}$ Hall (1969, p. 98). 
Antaeo, non crescere profuit Hydrae, v. 41); com a corsa de Cerínea que "as patas voadoras não salvaram" (nec cervam volucres eripuere pedes, v. 42); e por fim, de forma indireta, tem-se a alusão à busca dos pomos de ouro no jardim das Hespérides. Na verdade, o poeta preferiu mencionar, em quatro versos, o episódio de Hércules carregando o mundo, em lugar de Atlas, e o benefício dessa troca, pois "o mundo pendeu mais firme na hercúlea cerviz” (Firmior Herculea mundus cervice pependit, v. 47).

\subsection{A dedicatória a Florentino}

Para a maioria dos estudiosos, ${ }^{4}$ Florentino é um título honorífico dado ao general Estilicão, por seus feitos em favor da cidade de Florença. Estilicão, de fato, era o protetor de Claudiano e o financiou durante sua estadia na corte de Milão. O poeta dedica-lhe o livro II, com o epíteto de alter ego de Hércules (Tirynthius alter), o herói que inspirou Orfeu a voltar ao ofício musical, da mesma forma que Florentino/Estilicão o incentivou a continuar o longo poema.

\section{Análise métrica do prefácio do livro II: O dístico elegíaco}

Lamento e exaltação, substantivos que formam a segunda parte do título deste trabalho, são reações que caracterizam bem a expressividade do dístico elegíaco. Horácio, em sua Carta aos Pisões (Epistula ad Pisones), não sem razão denominada por Quintiliano de Ars Poetica, assim descreve esse esquema métrico, tão popular em Roma:

Em versos desigualmente unidos, primeiro lamentações,

depois também o sentimento votivo foi incluído.

Que autor, todavia, teria criado as curtas elegias, os gramáticos debatem e até agora a querela está sub judice.

(HORÁCIO, Epistula ad Pisones, vv75-8). ${ }^{5}$

Hinds (1987, p. 110), levando em consideração a formação do dístico, hexâmetro seguido de pentâmetro, assim o qualifica, “[...]

\footnotetext{
${ }^{4}$ Cf. Hall (1969, p. 98).

${ }^{5}$ Versibus impariter iunctis querimonia primum, / post etiam inclusa est uoti sententia compos/ quis tamen exiguos elegos emiserit auctor,/ grammatici certant et adhuc sub iudice lis est. Tradução de S. Bianchet, J. Avellar, B. Maciel e D. Monteiro.
} 
envolve uma fuga da grandeza épica e a união de um nível mais humilde em uma hierarquia de categorias poéticas". O poeta Ovídio, no início de seus Amores, ao expressar sua recusatio da poesia épica, filia o dístico elegíaco como metro adequado ao Cupido:

Armas, em grave ritmo, e violentas guerras preparava-me para cantar: matéria conveniente ao metro. Igual era o verso inferior - diz-se que Cupido teria rido e surrupiado um pé.

(OVÍDIO, $A m$. , vv. 1-4) ${ }^{6}$

E, continuando sua apreciação do metro, em sua medida desigual, expressa o efeito produzido, no poeta, pelo hexâmetro seguido do pentâmetro:

Quando bem se erige, com o verso primeiro, uma nova coluna, atenua o meu vigor o que vem depois.

(OVÍDIO, Am., vv. 17-9) ${ }^{7}$

E, para finalizar sua recusatio, entrega-se ao ethos amoroso do elegíaco metro e se despede da épica:

Abraso-me e, no vácuo peito, reina o Amor.

Em seis pés surja o verso, em cinco detenha-se:

férreas guerras com vossos metros, adeus!

Sejas coroada, em suas loiras têmporas, com o litorâneo mirto, oh Musa, por onze pés deves ser modulada!

(OVÍDIO, Am., vv. 26-30)

As palavras poéticas de Ovídio sobre o dístico elegíaco, tomadas com valor metapoético, permitem-nos reflexões que vêm confirmar as

\footnotetext{
${ }^{6}$ Arma gravi numero violentaque bella parabam/ edere, materia conveniente modis/ par erat inferior versus - risisse Cupido/ dicitur atque unum surripuisse pedem. Tradução da autora.

${ }^{7}$ Cum bene surrexit versu nova pagina primo,/ attenuat nervos proximus ille meos. Tradução da autora.

${ }^{8}$ Vror, et in vacuo pectore regnat Amor./ Sex mihi surgat opus numeris, in quinque residat:/ ferrea cum vestris bella valete modis!/ cingere litorea flaventia tempora myrto,/ Musa, per undenos emodulanda pedes! Tradução da autora.
} 
potencialidades dessa composição de versos desiguais. Os dois versos são correlacionados de tal forma que, no primeiro (prótase), cria-se um impasse que deve ser resolvido no segundo verso (apódose), menor e com cesura forte medial. Assim, o pentâmetro conduz ao encerramento da expectativa criada pelo hexâmetro, funcionando como prótase:

E, ainda que tenha preterido as délficas artes do deus, o loureiro vem atraído pelos órficos sons.

(CLAUDIANO, DRP, vv. 23-4) ${ }^{9}$

Por ti os líbicos golfos paralisaram, por ti a máxima Tétis tremeu, quando, a sustentar o polo, foste forçado.

(CLAUDIANO, DRP, vv. 45-6) ${ }^{10}$

Para realçar essa quebra de expectativa do pentâmetro, um dos recursos poéticos comumente empregados pelos poetas elegíacos é a rima interna ou leonina. Cria-se, no verso, uma espécie de eco, pois o íctus recai exatamente na fronteira da cesura e no final do verso pentâmetro. Cada um dos membros do sintagma nominal intercalado se posiciona nas extremidades dos hemistíquios: et Diomedeos // gramine pavit equos ("e de Diomedes, alimentou com grama, os cavalos", Prefácio, v. 12); pigrior astrictis // torpuit Hebrus aquis ("mais lento pelas estagnadas águas, o Hebro entorpeceu-se", v. 18); nec cervam volucres // eripuere pedes ("nem da corsa as voadoras patas salvaram" v. 42); horruit, imposito // cum premerere polo ("temeu, quando fosses premido pelo peso do céu" v. 46); lustrarunt umeros // Phoebus et astra tuos ("orbitaram os ombros teus, Febo e os astros" v. 48); excutis et placidos // ducis in orbe choros (“despertas e conduzes plácidos, em círculo, os coros" v. 52).

O dístico elegíaco tem interessante plasticidade. Ele pode conter em si uma ideia completa ou estender o raciocínio por mais versos, completando o sentido de um trecho do poema em dois ou quatro versos. Essa possibilidade de completude semântica em um único dístico é

\footnotetext{
${ }^{9}$ Cirrhaeasque dei quamvis despexerit artes,/ Orpheis laurus vocibus acta venit. Tradução da autora.

${ }^{10}$ Te Libyci stupuere sínus, te maxima Tethys/ horruit, imposito cum premerere polo. Tradução da autora.
} 
sedutora ao poeta de epigramas, por exemplo, ou ao poeta que pretende segmentar seu texto em porções de sentido com vistas à separação de ideias (enumerações, relações antitéticas, expressões em tópicos). No prefácio de Claudiano, ele explorou o recurso para relacionar os animais em harmonia:

Brandos, os molossos acariciaram a confiante lebre, e, vizinho ao lobo, a ovelha oferece seu flanco.

Concordes brincam com a malhada tigresa as corças, e de Massila os cervos não temeram a juba.

(CLAUDIANO, Prefácio do L. II, vv. 25-8) ${ }^{11}$

No campo do ordenamento das palavras, no pentâmetro, o poeta elegíaco pode brincar com arranjos sintáticos e semânticos que geram variações do tipo: 1) dois adjetivos no primeiro hemistíquio e verbo com os respectivos substantivos na ordem de concordância, no segundo $\left(\mathrm{A}^{1} \mathrm{~A}^{2} \mathrm{~V}+\mathrm{S}^{1} \mathrm{~S}^{2}\right)$ - Thracia pacifero contigit arua pede (v. 10); 2) um adjetivo e um substantivo, no primeiro hemistíquio, um substantivo e um adjetivo no segundo, com intercalação cruzada dos sintagmas, numa espécie de quiasmo visual $\left(\mathrm{A}^{1} \mathrm{~S}^{2} \mathrm{~S}^{1} \mathrm{~A}^{2}+\mathbf{V}\right)$ : Orpheis laurus vocibus acta venit (v. 24). Essa ordem, em que se topicalizam certos elementos do verso, longe de arbitrária e decorativa, revela rica significação: no primeiro exemplo, "Trácia" e "pacificador" antecipam informações sobre a chegada de Hércules, local e impacto; no segundo exemplo, "Orfeu" e "loureiro" colocam lado a lado o poeta por excelência e a árvore símbolo de Apolo, o deus da poesia. Ainda no pentâmetro, para realçar a alegria de Orfeu temos, 3) no primeiro hemistíquio, um sintagma completo e, no segundo, um sintagma intercalado por verbo: pollice festivo // nobile duxit ebur ("com o polegar festivo tocou a nobre lira", v. 16, grifos meus); 4) um nome grego de cinco sílabas ocupando o primeiro hemistíquio recebe, nesse local privilegiado, uma visibilidade especial: non Erymanthei // gloria montis aper ("não [o intimidou] o javali, glória do monte Erimanto", v. 36, grifos meus); e 5) encontra-se forma e sentido jogando com as

${ }^{11}$ Securum blandi leporem fouere Molossi/ uicinumque lupo praebuit agna latus;/ concordes uaria ludunt cum tigride dammael Massylam cerui non timuere iubam. Tradução minha. 
quantidades quando o poeta constrói, no hexâmetro, com sete longas a oração "as corsas brincam unidas", animais pacíficos e saltitantes, e, com maioria de sílabas breves, o sintagma ablativo "com a malhada tigresa", animal pesado e feroz: Cōncōrdēs vărīà lūdūnt cūm tīgrĭdě dāmmāe (v. 27): Cōncōrdēs Dāmmāe (cinco longas) lūdūnt (duas longas); vărīā tīgrĭdĕ (quatro breves, duas longas), sendo que o adjetivo varia forma um pé anapesto e o substantivo tigride, um dátilo, medidas antagônicas na sequência das quantidades vocálicas e no ethos. $\mathrm{O}$ anapesto confere à palavra um ritmo ascendente, de natureza dúbia e ofensiva (o adjetivo varia tem duplo sentido de variegado nas cores e dúbio no caráter); o dátilo, por sua vez, assegura a respeitabilidade do objeto retratado, no caso do temível animal. Verificamos outro exemplo do uso da sequência quantitativa para impactar o sentido quando o poeta concentra, no primeiro hemistíquio do pentâmetro, só palavras de sílabas longas, deixando as breves intercaladas às longas para o segundo. No caso em questão há o pareamento de Massylam (referência ao leão africano) com cervi. Evidentemente trata-se de uma aproximação insólita, exatamente a retratada no contexto pela magia dos acordes da lira de Orfeu. São cinco sílabas longas em sequência criando uma imagem acústica da gravidade do momento - leão e cervos no mesmo espaço: Māssȳlām cērvī nōn tǐmŭēerĕ iŭbăm ("de Massila os cervos não temeram a juba", v. 28).

\section{Considerações finais}

A escolha de Orfeu e Hércules para ilustrar o prefácio do livro II do De Raptu Proserpinae, em que o tema da harmonia do mundo é fundamental, revela a intenção do poeta de selecionar heróis humanistas e pacificadores.

Orfeu já descera ao mundo dos mortos para resgatar Eurídice; por amor venceu as trevas e com a magia da música convenceu os tiranos do Inferno. Hércules, por sua vez, desafiara o guardião do Orco, Cérbero, indo e voltando do reino dos mortos, após capturá-lo e devolvê-lo.

O metro escolhido para o prefácio, o dístico elegíaco, também se mostra adequado, uma vez que, em forma de hino, o canto de Orfeu serve de prelúdio para a narrativa épica. Além disso, a chegada de Hércules à 
Trácia, cantada pelo vate, é um verdadeiro carmen triumphale ("poema de triunfo"). Os recursos poéticos que a combinação do hexâmetro com o pentâmetro oferece ao poeta elegíaco dão ao poema a capacidade de expressão do lamento e da exaltação. As rimas internas com seus ecos enfáticos, as aproximações insólitas dos vocábulos de sentidos antitéticos nos hemistíquios dos pentâmetros, os jogos das quantidades, antepondo sequência de longas e breves, ritmos solenes e pueris, dentre outras possibilidades, revelam como a elaboração do dístico ganha em engenhosidade.

\section{Referências}

CAMERON, A. Claudian: Poetry and Propaganda at the Court of Honorius. Oxford: Claredon Press, 1970.

CLAUDIAN. De Raptu Proserpinae. Edited with an introduction and comentary by J. B. Hall. New York: Cambridge, 1969.

CLAUDIEN. Oeuvres: Tome I - Le Rapt de Proserpine. Texte établi et traduit par Jean Louis Charlet. Paris: Les Belles Lettres, 1991.

HYGIN. Fables. Texte établi et traduit par Jean-Yves Boriaud. Paris: Les Belles Lettres, 2003.

HINDS, S. The Metamorphosis of Persephone: Ovid and the SelfConscious Muse. Cambridge: Cambridge University Press, 1987.

HORÁCIO. Epistula ad Pisones. Tradução de S. Bianchet; J. Avellar, B. Maciel e D. Monteiro. Edição bilíngue. Belo Horizonte: FALE/UFMG, 2013. (Livros Viva Voz).

MARRÓN, G. El rapto de Prosérpina: un nuevo contexto para la trama épica. Buenos Aires: Ediuns, 2011.

TOOHEY, P. Reading Epic: An Introduction to the Ancien Narratives. London/NewYork: Routledge, 1992.

Recebido em: 20 de setembro de 2018. Aprovado em: 28 de novembro de 2018. 